\title{
Uncovering the needs and wants of end-users towards green apps: A Living Lab approach
}

\author{
Annabel Georges \\ Department of Communication Sciences \\ iMinds - MICT - Ghent University \\ Ghent, Belgium \\ Annabel.georges@iminds.be \\ Dimitri Schuurman \\ Department of Communication Sciences \\ iMinds - MICT - Ghent University \\ Ghent, Belgium \\ Dimitri.schuurman@iminds.be \\ Maarten Desmet ${ }^{1}$ \\ Faculty of Architecture and the Built Environment OTB \\ Delft University of Technology \\ Delft, Netherlands \\ m.desmet@tudelft.nl
}

\begin{abstract}
One of the biggest societal challenges is to reduce the impact on the environment [1]. During the last years a lot of digital tools and green apps have been developed in order to help individuals to lower their ecological footprint. These green applications can make use of the specific functionalities of smartphones such as mobility, smartness and connectedness in order to provide better and more personalized services [2-3]. However these applications mostly focus on one aspect of sustainability, such as transportation or electricity consumption. Moreover user research concerning the users' needs and wants towards these applications is lacking or is limited to only one research step such as testing a prototype version [3]. One approach in which end-users are involved intensively is the Living Lab approach. Therefore within this paper we will explore the role of Living Labs as an innovation intermediary in the research into green apps and more specific on the needs and wants of end-users concerning green apps. Therefore we conducted a single case study research of a Living Lab project in which the ecological footprint of end-users is being measured based on their transportation, housing as well as consumption. We argue that the Living Lab approach adds added value for conducting research on green apps because the user plays a central role within this research which makes it possible to adapt the service to the needs and wants of end-users through an iterative approach. Which is important seen the need of personalized green apps. Next to this the role of Living Labs as intermediary also assisted into the development of the green app.
\end{abstract}

Keywords-Living Labs, Green Apps, User Research, Proenvironmental behavior, Innovation Intermediary, User Involvement

\footnotetext{
${ }^{1}$ Acknowledgement: Together with Koen Jaspers, Maarten Desmet founded For Good, an application to guide users toward a sustainable lifestyle. Within this paper, this application is used as case-study.
}

\section{INTRODUCTION - PRO-ENVIRONMENTAL BEHAVIOR}

One of the biggest societal challenges of today is to create a more sustainable environment. Next to governmental decision-making, individuals are also responsible for their impact on the environment. Approximately thirty to forty percent of the environmental degradation is due to private household consumption activities [4]. Therefore it is relevant to stimulate this pro-environmental behavior. Pro-environmental behavior can be defined as "behavior that consciously seeks to minimize the negative impact of one's actions on the natural and built world (e.g. minimize resource and energy consumption, use of non-toxic substances, reduce waste production)" [5]. Pro-environmental behavior is shaped by internal and external factors [5]. Internal factors include a persons' personality traits, value system and environmental consciousness. This pro-environmental consciousness consist of environmental knowledge, values, and attitudes, together with emotional involvement. External factors include infrastructure, political, social, cultural and economic factors. Next to these factors, several barriers are identified. The biggest barriers are the old behavior patterns of individuals, lack of external/internal incentives, lack of environmental consciousness and negative of insufficient feedback about behavior [5]. When studying the reasons for choosing and rejecting ethical products, impact, relevance, health, savings and quality are seen as the main reasons for choosing ethical products. The main reasons why people reject ethical products are confusion about what makes a product ethical, expensiveness, skepticism, indifference and the fact that you have to go to special stores [6].

In the literature it thus becomes clear that a complex mix of several factors play a role in the green behavior of individuals. This also reflects on the literature about green and ethical consumers. In a paper to structure the characteristics of green consumers based on previous research, Nair [4] emphasizes that a lot of complexities are involved in profiling green consumers. For example, socio-demographic characteristics are used a long time to profile the green consumer, however these characteristics are rather equivocal and are unreliable predictors of green behavior. It is thus extremely difficult to standardize the profile of a green consumer because consumers do not need to have environmental knowledge to be concerned about the environment and opposite, some consumers buy green products while they are less environmentally concerned [4].

In general, studies have shown an increase in environmental values and belief, however Kennedy and her colleagues [7] argue that increases in environmentallysupportive behavior are less observed. Therefore they introduce 'the environmental values-behavior gap'. This gap argues that there is a difference between the pro-environmental values of consumers and their environmentally-supportive behavior. 
Individual, household and societal factors can explain this gap. The individual factors can be related to the internal factors of the model of pro-environmental behavior [5]. The household and societal factors can be related to the external factors. From previous research, it becomes clear that a complex mix of factors play a role in the pro-environmental behavior of people. And although some people tell that they will behave more ecological, the environmental values/behavior gap learns that there is a big difference between what people tell and what people do. One way of learning how people can be stimulated to perform more pro-environmental behavior is by studying models of behavior change. One well-known model is the model of Fogg. Fogg argues that "for a target behavior to happen, a person must have sufficient motivation, sufficient ability, and an effective trigger" [8]. Important within this theory is that all the factors need to occur at the same time in order to facilitate the desired behavior. Within green behavior, motivation can be related to intrinsic motivations, the impact of green behavior on the environment, and for example because people belief it is healthier to conduct green behaviors. Ability can for example be related to the financial situation of endusers, the extent to which people are informed about green behaviors and the possibility to have access to green products. When applying green behavior on the model of Fogg, it is for example possible that a consumer is very motivated to buy more green products, however the ability can lack because of not knowing which products are more sustainable. Therefore for example an information trigger during the purchase can stimulate the ability for consumers to buy sustainable products.

Information systems can help people to fulfill their good intentions when it comes to the environment by providing information and tools using "efficiency systems, forecasting, reporting and awareness, energy efficient home computing, and behavior modification" [9]. The transformative power of information systems should be used in order to develop a more sustainable society [10]. Within the information system literature the study of the use of smartphones in the search of a sustainable information technology agenda has gained more attention [11]. Smartphones have the mobility, connectivity and smartness to potentially facilitate green behavior [2-3]. This mobility makes it possible to give a certain trigger at the right time and place. For example connectivity makes it possible for end-users to receive contextual information and share information anytime and anywhere. At last, the smartness makes it possible to better understand the end-users. Based on previous research by Coşkun and Erbuğ [3] on the use of smartphones as persuaders for pro-environmental behaviors, seven persuasion techniques are explored. These techniques are eco-feedback (1); reminder (2); reward (3); self-monitoring tool (4); social learning and facilitation (through social media) (5); suggestion (6) and trigger (7). The key element in using a smartphone application as persuader for pro-environmental behavior is personalization and the applicability to the personal needs of the end-users. However, the authors argue that research about "how users experience with commercial applications and how their preferences influence their experience would contribute to the field"'[3]. Within their paper Coşkun and Erbuğ study the adoption and domestication of several green apps with end-users in order to develop their model for sustained usage of smartphone applications as persuaders. The authors argue that this differentiates their methodology in comparison with other research that mostly is concentrated on designing and testing an initial prototype. However the authors argue that in order to make a personalized service, "diverse methodologies will be required to derive similarities and differences between users to achieve an optimized level of personalization" [3]. Because of the importance of personalization and to situate the needs and wants of end-users it is extremely useful to involve end-users during the whole product development process.

Within the literature on green apps only few papers mention to give end-users a central role during the innovation development of green apps. An example is the research of Jakobi and Schwarts [12], they describe their early results of the end-user involvement during the research and design process of an eco-feedback technology. The authors hope to pave the way for an increased consideration of end-user development in this domain. Next to this paper, little research has been conducted in which end-users play a central role. However, customer integration is seen as key for enhanced innovation processes [13]. By involving end-users and studying them in their everyday lives, better insights into the possibilities and restrictions of innovations are generated [14]. One approach in which end-users (and other stakeholders) are intensively involved is the Living Lab approach. Living Labs are structured innovation ecosystems in which innovations are being developed in cooperation with all relevant stakeholders [15]. This approach helps to structure and govern user involvement in the innovation development process [16]. Although there is still some theoretical discussion on the actual definition of a Living Lab, most authors agree that it is a way to involve end-users in the development of an innovation over a longer period of time using a combination of different research methods, following an iterative process [17]. Almirall and Wareham, two of the most prolific and influential authors in the Living Labs field, state that "Living Labs are semipartitioned spaces in the form of innovation arenas integrated in real-life environments but separated by means of an innovation project structure that cultivate user-led insights" and "Living Labs are fundamentally infrastructures that surface tacit, experiential and domain-based knowledge such that it can be further codified and communicated" [18]. However some challenges emerge when involving users during innovation research (especially within radical innovation), such as cognitive limitation that can hinder the users to give a valuable input or the fact that users are constrained in their creative thinking; User needs are latent and therefore they are more difficult and costly to transfer; and the fact that many users have a natural resistance to change [19].

Katzy and his colleagues [20] also state that there is broad agreement in literature that innovation processes in open networks are coordinated through a visible hand, often referred to as innovation intermediary, and propose the Living Lab as a process coordinating innovation intermediary for '(1) closing the pre-commercial gap by manifesting initial demand for products and services, as well as (2) orchestrating the actions of disparate actors in order to gain critical mass for the creation of a product or service' $[18 ; 20]$. These innovation intermediaries are described to provide a set of operative activities that link 
them to the network innovation processes, but literature provides only fragmented insight about the intermediaryprocess relationship. Sieg, Wallin and von Krogh [22] also note that there is a relatively limited understanding of the implementation of Open Innovation through innovation intermediaries, with the notable exceptions of knowledge brokers (recombination of existing solutions) [23-24], and virtual knowledge brokers [25]. Moreover, Smits and Kuhlmann note that the most systemic instruments, such as brokers and intermediaries, take an individual organization or a bilateral relation as unit of analysis, focusing mostly on the private sector and far less on the public sector and publicprivate alliances, with only few attention for learning processes, platforms for experimentation or tailor-made strategic intelligence [26].

Because of the lack of research about innovation intermediaries and the study about how to gather users' needs and wants towards green apps, we will explore the added value of Living Labs as innovation intermediary during the development of green apps with end-users.

\section{RESEARCH APPROACH}

\section{A. Case-study analysis}

Within this paper we will investigate the role of Living Lab research during the development of a green app. This will be studied by conducting a case-study analysis. Case study research excels at bringing an understanding of a complex issue and can extend knowledge or add strength to what is already known through previous research [27-28]. Yin defines the case study enquiry as follows: "The case study enquiry (1) copes with the technically distinctive situation in which there will be many more variables of interest than data points, and as one result (2) relies on multiple sources of evidence, with data needing to converge in a triangulation fashion, and a another result (3) benefits from the prior development of theoretical propositions to guide data collection and analysis." [29]. Within this case-study analysis, we will discuss the Living Lab case 'For Good', an ecological smartphone application that coaches individuals to lower their ecological footprint. The Living Lab research was conducted by iMinds - Living $\mathrm{Labs}^{2}$, the Living Lab division of the iMinds research institute ${ }^{3}$ situated in Flanders (the Dutch speaking northern part of Belgium). For Good was partially funded by Enterprise Flanders, a government agency that helps entrepreneurs and investors to establish or expand a business in Flanders ${ }^{4}$ and the Federal Institute for Sustainable Development ${ }^{5}$. The Living lab case started in January 2014 and finished in December 2014. The data for the case study analysis was gathered through project documents, an interview with the instigators and results from the different research phases during the Living Lab. In the next two sections we will describe the For Good application (at the moment of the
Living Lab) in detail and we will explain the main elements of the Living Lab constellation.

\section{B. For Good}

For Good is a smartphone application aiming to stimulate pro-environmental behavior. As opposed to other green apps, For Good measures the ecological footprint of their end-users based on their housing, transportation as well as their consumption. For each category a separate footprint is calculated. Housing is calculated by factors such as, energy consumption, gas consumption and the infrastructure of the building. In the prototype, transportation is measured by the total amount of kilometers by foot, car, public transportation and bicycle and the number of airplane travels. Finally consumption is measured by counting the ecological footprints of the products an end-user purchased in the retailer supermarket. By taking a picture of their purchase ticket with the app, For Good recognizes the product lines (because the test version was a prototype, this was only possible for vegetables, beverages and fruit), calculates the footprint in the back-end and pushed this information into the profile of the user. In the future For Good hopes to skip this step by linking to loyalty cards. Next to the three separate footprints, a total footprint per user is being measured (Fig. 1). This measurement can be used to track changes in the ecological footprint over time. The unit of measure used by the FG app is 'planets'. The number of planets in the user's profile symbolizes the amount of planets we would need to provide our needs if everybody would make the same choices regarding (sustainable) consumption as the user does. The choice for this unit of measure is made to link individual choices to the impact it has on a global scale. Next to the selfmonitoring function, end-users also receive tips per subject, based on their profile. More concretely for consumption an ecological footprint score is given to each product. Based on five subcategories (i.e. ingredients, conservation, packaging, transport and seasonal), products with a lower ecological footprint are suggested. This application differs from other green apps because it takes into account the ecological footprint of housing, transportation as well as consumption.

Moreover, based on the abilities of the user, improvements can be measured in each category. For example users living in a rented house can experience more difficulties to lower their impact in the category of housing, they can put extra effort in the other two categories. The functionalities of For Good as described above are related to the prototype. In order to develop the For Good application and its functionalities, a Living Lab research was conducted.

\footnotetext{
${ }^{2}$ https://www.iminds.be/en/succeed-with-digital-research/living-lab

${ }^{3} \mathrm{http}: / / w w w . i m i n d s . b e / \mathrm{en}$

${ }^{4} \mathrm{http}: / / \mathrm{www}$.agentschapondernemen.be/english

${ }^{5}$ http://fido.belgium.be/nl
} 


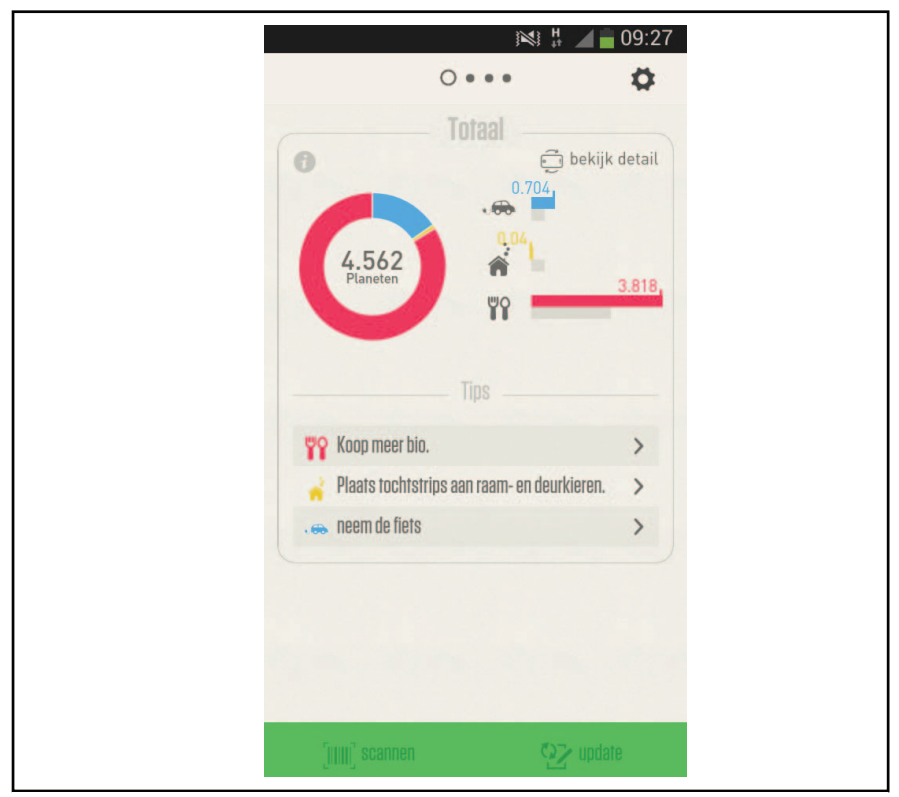

Fig. 1. Screenshot For Good - Total ecological footprint

\section{FINDINGS}

First we will dig deeper into the different elements of the Living Lab infrastructure and how they can bring an added value for the For Good case. Instead of defining Living Labs, Schuurman and his colleagues developed a conceptual model of a Living Lab constellation [30]. They argue that the Living Lab infrastructure is characterized by five elements (i.e. natural setting, multi-method, medium- to long-term, usercentric and multi-stakeholder). Subsequently an in-depth analysis will be made of the role of the Living Lab as intermediary in the innovation process for green apps.

\section{A. Living Lab as research approach for developing green apps}

In contradiction to one shot research, this Living Lab research ran over a medium- to long term. At the beginning of the Living Lab, For Good was still in its concept phase, however at the end of the Living Lab a prototype was build that has been tested by end-users. During the Living Lab different stakeholders were involved. The main important stakeholders are the instigators, the end-users, the researchers (userresearch as well as business model researchers), panel managers and the developers of the application. During the research the different stakeholders came together before each research step in order to communicate the main research results and to further iterate the application. This collaboration between multiple stakeholders is a characterizing element of the Living Lab approach.

This iteration was also made possible because of the multimethod approach of the Living Lab research. During the different research phases of the Living Lab, the end-users played a central role. Their feedback was used during the development of For Good. Therefore this approach was usercentric.

Following research steps took place:

1) Kick-off meeting: During this meeting the main research questions were defined and a validation board ${ }^{6}$ workshop was held in order to make a first mapping of the different customer segments and their wants and needs. Besides this some practical agreements were made between the different stakeholders

2) State of the Art: In this phase the main purpose is to get a view on the current competitors and knowledge within the innovation domain (i.e. green apps).

3) Intake-survey: This survey was completed by 211 respondents and the main goals was to segment the respondents according to their attitude and knowledge towards ecology and digital apps and to introduce For Good in order to get a first feedback loop on the innovation. This survey showed that users are concerned about ecology, but they scored lower on items concerning taking actions to increase green behavior and to communicate and share ecological information. The users are especially searching for practical green tips and information. The functionality to monitor your own ecological footprint is seen as one of the main important functionalities of For Good. As opposed to the expected assumptions, users are in general less interested to share their ecological footprints with others via social media. Because of the outcomes of previous research [4] it is clear that the variables of pro-environmental behavior of end-users differ and that socio-demographics are not the ideal parameters to make a market segmentation [3]. Therefore four user profiles based on the ecological knowledge, awareness, concern and interaction with others concerning ecology are created. These are used to further recruit participants during the Living Lab.

4) Co-creation: During this co-creation, creative methods were used in order to let participants think about their needs and wants towards green apps. A lot of internal and external factors and barriers towards pro-environmental behavior were uncovered. For example for mobility you are sometimes limited in the options (e.g. limited public transportation; cheap plane tickets); it's expensive to live more ecologic and it is difficult to always think of the most ecologic possibility. The users wanted clear information, cheap ecological tips, more information about local, biologic and fair trade products and especially a service that require a minimum of time effort. Subsequently the For Good application was introduced and more qualitative and in-depth feedback towards the app was generated about gamification, sharing, privacy and a ranking of interesting functionalities. The end-users agreed that is it important to find a balance between consumption, housing and transportation, but they had the most interest in consumption. These results gave insights in what users want to integrate in the application. For example triggers to remind them to act

\footnotetext{
${ }^{6}$ https://www.leanstartupmachine.com/validationboard/
} 
ecologically and an app that gives you detailed feedback without investing a lot of time in it.

5) Prototype testing: During this phase a prototype of the app was first tested by five test-users. They came together in a kick-off session in which they has the opportunity to give their first feedback to the developers and instigators. Then, this group tested the application for four weeks, with several iteration loops. After this group has tested he application, a second group of five users tested it for four weeks. In contrary to the first group, this group did not came together before the test-period. During the test-phase the respondents had to fill out weekly surveys (pre/post-survey, first impression of the app, quality of experience, personalization and gamification) and did telephone interviews with the test-users. The test-users could test the innovation in their natural setting. By testing the innovation in the real-life context, we believe that more naturalistic behavior could be measured concerning the domestication of For Good and the social interactions related to the application. The field trial revieled that the innovation was to immature te engage people for a longer period. Some test-users were not engaged enough to start testing the innovation after their first contact with it. One person for example stopped testing because the application did not take into account the ownership of solar panels. Test-users notified a lack of personalized tips and would be eager to give more personal information to get more personalization. It also became clear that the application was to general. For example users that already performed a lot of pro-environmental behavior, were less stimulated to use the app because certain behaviors could not be monitored. And for example students could only use the consumption part of the application. Therefore it was suggested to set your own goals in the app. From the test-phase it also became clear that people stopped using the application after a certain amount of time because of technical issues but also because they did not received enough triggers to keep using the app.

6) Evaluative co-creation session: After the test-phase all the participants were invited to a evaluative co-creation session to share their experiences about For Good. However, only three out of ten of the participants attended this session. The main purpose here was to generate insights in the natural use of the application in the use-context of the users and to get some answers on the results from previous research steps. For example one respondent argued that she barely followed the tips, however because of the use of the app she was more aware about possible pro-environmental behaviors and she performed other pro-environmental behavior. Another participant had some discussion within his family about ecology and the buying of bottled water. This resulted in new recommendations to change and iterate the application.

As suggested by Frissen [21] triangulation of methods and a contextualization of use are methods to overcome the barriers of user involvement in innovation research. Within this Living Lab research, research methods were triangulated and after each research step and even within research steps (i.e. prototype testing) there was a constant iteration. At the end of the research the user-context was taken into account because test-users could test the application in their own use-context. Without the intake survey and the co-creation session there was a big chance that the prototype would be less fitted to the wants and needs of the test-users. By conducting the different research steps, other sorts of information can be gathered. During the intake-survey especially general information about the needs and wants of end-users was gathered and this information was discussed more in-depth during the cocreation, which also offered information about the functionalities of the application. During the kick-off of the prototype-testing especially information about the userfriendliness was gathered, where after the prototype testing especially contextual information about the use was obtained. Because of the gathering of these different kinds of information and the iteration and segmentation of the user needs, a more personalized service could be created, which is necessary for green apps. For example during the intake survey four personae were made to make a distinction between the respondents concerning their attitude and knowledge towards ecology and the importance to share ecological information with others. During the recruitment of the participants of the field trial and the co-creation session, these personae were used to recruit participants. However, although some different user-profiles attended these research steps, we also noticed that it is more difficult to involve users that are less interested in ecology.

From a pre-assessment and post-evaluation with the instigators of For Good concerning the expectancies and final outcomes of the Living Lab some interesting findings are generated about the added value of Living Lab research. From the interviews it became clear that the Living Lab substantively more defined the directions and outcome of the service than expected. Especially information about the needs of end-users and evaluative information was gathered during the research. To a lesser extent technical solution information and user innovation were captured. However the instigators used the results from the Living Lab for several purposes such as their marketing strategy, business model, innovation development and to increase the internal knowledge within the company.

\section{B. Living Lab as an intermediary}

Besides the information that was directly gathered from the user involvement and the triangulation of research methods, the role of the Living Lab as an intermediary also facilitated the development of the application. For example at the end of the Living Lab the instigators decided to focus on another market segment. This change had an impact on the business model of For Good. However although also external factors played a role in this business model change, this was also due to the intensive contact and interaction with endusers. Between the different research phases the researchers and instigators (and sometimes developers and business 
modeling) met to discuss the results in order to iteratively develop the innovations and the business model.

Next to the added value of the research itself, the Living Lab helped the instigators to be constantly working on the innovation. The instigators of For Good had a full time job next to the development of their innovation. Because of the user-research and the constant interactions between the different stakeholders, the instigators mentioned they were extra stimulated to work on the innovation and to for example start to make a prototype.

In comparison with one shot research the Living Lab approach facilitates intensive interaction between the different stakeholders which also allow to iterate the application and go back to end-users to further iterate the application. For example during the field trial, the end-users gave feedback to the researchers and the researchers converted this input into recommendations that was directly send to the developers. During this iteration process there is a constant check between the needs and wants of end-users and the innovation. By using this approach there is a smaller chance that a product is being developed that does not respond to the needs and wants of end-users. These results are far more difficult to achieve during a one-shot research just before the launch of an innovation for example. Within this process it is the role of the researcher to translate these user needs in concrete recommendations for developers of the application.

\section{CONCLUSION}

Within this paper we explored the added value of Living Lab research during the development of green apps. We started with a literature review in which it became clear that there are a lot of factors that play a role in pro-environmental behaviors [5]. Therefore it is important that green apps can be personalized. In order to create personalized services it is important to use diverse methods to segment the groups of end-users to create an optimized level of personalization [3]. Therefore end-users need to be involved during the development of greens apps. To overcome the barriers of user involvement, contextualization and triangulation of research methods are important [20]. We propose Living Labs as an appropriate method to research the user needs of green apps because of several reasons.

First quantitative as well as quantitative research methods are used to explore the needs and want of end-users. By conducting an intake-survey, the participants can be segmented and the first basic needs and wants of end-users are generated. However, surveys cannot go in-depth and therefore more qualitative research methods are recommended. By using the qualitative research methods such as the cocreations, kick-off of the field trial and the field trial, more indepth results are gathered from the end-users. This iteration, typical for Living Lab research, and gathering of different kinds of information about the innovation allows to create a green app that is more adapted to the needs and wants of the end-users. Secondly, the contextualization by letting users test the innovation in their natural use-context provoke new elements that should be included in the application (e.g. personalized triggers). Next to this the role of a Living Lab as an intermediary also generates other advantages such as forming a link between end-users and instigators. By bringing those two actors together, they both can learn from each other. Next to that the Living Lab research and the involvement of end-users also stimulated the instigators to constantly work on the innovation. By involving multiple relevant stakeholders, using a multi-method and user-centric approach, and including the natural use-context in a medium- to long-term, we believe that Living Labs can provide an added value to the development of green apps that are characterized by their personalized approach and their complexity.

However, we it is difficult to generalize the results of this case-study analysis to other cases. Moreover also during the Living Lab research, some problems turned up. For example we noticed that it is harder to find people that are willing to participate in a project about ecology. Through this, there was no opportunity to select the most suitable participants and thus the majority of the participant had already a very green profile.

Future research should further examine the (added) value of Living Labs in the development of green apps. Therefore it is relevant to compare different Living Lab cases about green apps. Next to this Living Lab participants are the experts in this special application domain [12], and thus also more research can be conducted on how to keep participants motivated to participate in Living Lab research about green apps. Finally, personalization is one of the most important aspects for end-users towards green apps. However, more research is needed to investigate how green apps can be personalized without requiring a lot of effort from the enduser. 


\section{References}

[1] Meadows, D. (1972). The Limits to growth. New York: Universe Books.

[2] Fogg, B. \& Eckles, D., eds, Mobile Persuasion: 20 Perspectives of the Future of Behavior Change. Stanford Captology Media, 2007

[3] Coşkun, A. \& Erbuğ, C. (2014). Designing for behaviour change: smart phone applications as persuaders of pro-environmental behaviours. METU JFA, 31(1), p. 215-233

[4] Nair, P. B. (2015). Profiling Green Consumer Characteristics: An Eternal Quandary. Journal of Advanced Management Science Vol, 3(2).

[5] Kollmuss, A. \& Agyeman, J. (2002). Mind the gap: why do people act environmentally and what are the barriers to pro-environmental behavior?.Environmental education research, 8(3), 239-260.

[6] F. Burke, P., Eckert, C., \& Davis, S. (2014). Segmenting consumers' reasons for and against ethical consumption. European Journal of Marketing, 48(11/12), 2237-2261

[7] Kennedy, E. H., Beckley, T. M., McFarlane, B. L. \& Nadeau, S. (2009). Why we don't" walk the talk": Understanding the environmenta values/behaviour gap in Canada. Human Ecology Review, 16(2), 151

[8] Fogg, B. J. (2009, April). A behavior model for persuasive design InProceedings of the 4th international Conference on Persuasive Technology (p. 40). ACM

[9] Cazier, J. A. \& Hopkins, B. E. (2011). Doing The Right Thing for the Environment Just Got Easier With a Little Help from Information Systems. Proceedings of SIGGreen Workshop. Sprouts: Working papers on Information Systems, 11(10).

[10] Watson, R. T., Boudreau, M. C., \& Chen, A. J. (2010). Information systems and environmentally sustainable development: energy informatics and new directions for the IS community. Management Information Systems Quarterly,34(1), 4.

[11] Pitt, L. F., Parent, M., Junglas, I., Chan, A., \& Spyropoulou, S. (2011). Integrating the smartphone into a sound environmental information systems strategy: Principles, practices and a research agenda. The Journal of Strategic Information Systems, 20(1), 27-37.

[12] Jakobi, T., \& Schwartz, T. (2012, October). Putting the user in charge: end user development for eco-feedback technologies. In Sustainable Internet and ICT for Sustainability (SustainIT), 2012 (pp. 1-4). IEEE.

[13] Levén, P. \& Holmström, J. (2008). Consumer co-creation and the ecology of innovation: A living lab approach. In Public systems in the future: possibilities, challenges and pitfalls.

[14] Schumacher, J. \& Feurstein, K. (2007, June). Living Labs-the user as co-creator. In ICE 2007 Proceedings: 13th International Conference on Concurrent Enterprising, Sophia Antipolis, France. The Free Press.

[15] Feurstein, K., Hesmer, A., Hribernik, K., Thoben, T. \& Schumacher, J. (2008). Living Labs: a new development strategy. In J. Schumacher \&
V. P. Niitamo (Eds.), European Living Labs - a New Approach for Human Centric Regional Innovation. Berlin, Germany: Wissenschaftlicher.

[16] Almirall, E. (2008). Living Labs and open innovation: roles and applicability. The Electronic Journal for Virtual Organizations and Networks, 10, 21-26.

[17] Schuurman, D., Lievens, B., De Marez, L. \& Ballon, P. (2012). Towards optimal user involvement in innovation processes: A panel-centered Living Lab-approach. In Proceedings of PICMET'12 (pp. 2046-2054).

[18] Almirall, E., \& Wareham, J. (2011). Living Labs: arbiters of mid-and ground-level innovation. Technology Analysis \& Strategic Management, 23(1), 87-102

[19] Lettl, C., Herstatt, C., \& Gemuenden, H. G. (2006a). Learning from users for radical innovation. International Journal of Technology Management, 33(1), 25-45.

[20] Katzy, B., Turgut, E., Holzmann, T. \& Sailer, K. (2013). Innovation intermediaries: a process view on open innovation coordination. Technology Analysis \& Strategic Management, 25(3), 295-309.

[21] Frissen, V. A. (2000). ICTs in the rush hour of life. The Information Society, 16(1), 65-75

[22] Sieg, J. H., Wallin, M. W., \& Von Krogh, G. (2010). Managerial challenges in open innovation: a study of innovation intermediation in the chemical industry. $R \& d$ Management, 40(3), 281-291.

[23] Hargadon, A., \& Sutton, R. I. (1997). Technology brokering and innovation in a product development firm. Administrative science quarterly, 716-749.

[24] Hargadon, A. and R. I. Sutton (2000). "Building an innovation factory." Harvard business review 78(3): 157-166, 217.

[25] Verona, G., Prandelli, E., \& Sawhney, M. (2006). Innovation and virtual environments: towards virtual knowledge brokers. Organization Studies, 27(6), 765-788

[26] Smits, R. \& Kuhlmann, S. (2004). The rise of systemic instruments in innovation policy. International Journal of Foresight and Innovation Policy, 1(1), 4-32.

[27] Yin, R. (1984). Case study research. Beverly Hills, CA: Sage Publications.

[28] Eisenhardt, K. (1989). Building theories from case study research. Academy of management review, 14(4), 532-550.

[29] Yin, R. K. (2009). Case Study Research: Design and Methods. Thousand Oaks, California: SAGE publicationis, Inc.

[30] Schuurman, D. Baccarne, B., Kawsar, F., Seys, C., Veeckman, C., De Marez, L., \& Ballon, P. (2013). Living labs as quasi-experiments: results from the Flemish LeYLab. In XXIV ISPIM Conference: Innovating in Global Markets: Challenges for Sustainable Growth. 